\title{
THE MORPHOLOGICAL APPEARANCE AND DEVELOPMENT OF SHEEP OVA FERTILIZED BY SURGICAL INSEMINATION
}

\author{
I. D. KILLEEN* AND N. W. MOORE \\ Department of Animal Husbandry, University of Sydney, \\ McCaughey Memorial Institute, Jerilderie, N.S.W.
}

(Received 17th February 1970)

\begin{abstract}
Summary. Two experiments are described in which were studied the morphological appearance and the subsequent development of sheep ova fertilized by uterine insemination. Ewes were naturally mated, or inseminated with freshly ejaculated semen, either whole or following removal of the seminal plasma, or with semen recovered from the uteri of naturally mated ewes ('uterine semen'). Fertilized eggs were collected after insemination or mating and were either stained and examined or transferred to recipient ewes.

Uterine insemination with whole or fractionated semen gave very high rates of fertilization. 'Uterine semen' gave a low fertilization rate due to poor quality samples. The proportion of eggs fertilized by uterine insemination which developed into lambs or embryos was similar to that of eggs collected from ewes naturally mated. Treatment of semen before insemination had no effect upon subsequent development of fertilized eggs.

More than $50 \%$ of the fertilized eggs contained anucleate particles, but neither the method of mating (uterine insemination or natural mating) nor treatment of semen before insemination had any major effect upon the incidence of such eggs. The presence of anucleate particles did not preclude subsequent normal development.

It is concluded that the low lambing percentages recorded following uterine insemination are not due to fertilization failure or abnormalities of fertilization, but to surgical interference with the tract resulting in expulsion or rapid transport of fertilized eggs.
\end{abstract}

\section{INTRODUCTION}

Surgical insemination of the ewe, involving the direct injection of semen into either the Fallopian tubes or the uterine horns, has been shown to give high rates of fertilization but subsequent lambing performances have been poor (Salamon \& Lightfoot, 1967; Mattner, Entwistle \& Martin, 1969; Killeen,

* Present address: Agricultural Research Station, Leeton, N.S.W. 
1969). Salamon \& Lightfoot (1967) and Mattner et al. (1969) suggested that the differences between fertilization and lambing were due to excessive embryonic loss. However, their studies provided no direct evidence on the fate of eggs fertilized by surgical insemination.

Either or both of two explanations may account for the large discrepancy between fertilization and lambing performances, namely, the direct effects of surgical insemination on the egg or on the genital tract.

The first explanation gains some support from the work of Killeen (1969), who found that a number of eggs fertilized by surgical insemination contained small anucleate particles. The incidence of these so-called 'abnormal' eggs could account for some, but not all, of the difference between fertilization and lambing performance. However, the study provided no direct evidence on the viability of the 'abnormal' eggs. Surgical insemination places all the components of semen within close proximity of recently ovulated eggs and it is possible that components which are normally lost or diluted during passage from the vagina to the tubes are present in sufficient concentration to have a deleterious effect upon the viability of fertilized eggs. In the rabbit, there is suggestive evidence that high concentrations of seminal plasma can affect the development of fertilized eggs (Chang, 1950; Hadek, 1959). Freshly ejaculated semen probably contains a number of spermatozoa, which by nature of their age and other characteristics may be classed as only partially competent. Such spermatozoa may well lose their viability during passage through the tract but, with surgical insemination, they could actively compete with 'fully competent' spermatozoa. Eggs fertilized by partially competent spermatozoa, however, may not possess the capacity for full development.

The second explanation depends upon the assumption that surgery and the consequent manipulation of the tract result in failure of eggs to enter the Fallopian tubes or in rapid transport of fertilized eggs to the uterus, a site known to provide an environment unfavourable for 'underdeveloped' eggs (Averill \& Rowson, 1958; Moore \& Shelton, 1964).

\section{MATERIALS AND METHODS}

\section{Experimental animals and design}

A flock of 500 mature cyclic Merino ewes, sixteen vasectomized rams and six entire rams of proven fertility were used in two experiments designed to study the morphological appearance and the subsequent development of eggs fertilized by uterine insemination. The ewes were run with the vasectomized rams and they were inspected for oestrus twice daily at 06.00 and 18.00 hours.

The design of the experiments is shown in Table 1. Fertilized eggs were collected from donor ewes which had been previously treated with 1000 to 1200 i.u. pregnant mare's serum gonadotrophin on the 12th to 14th day of the oestrous cycle and the eggs were either examined after staining with $1 \%$ orcein, or they were transferred to recipient ewes. In Exp. 1, embryos were recovered on the 16th day after oestrus, while in Exp. 2, recipients were allowed to go to term. 
Treatment of semen and insemination

Apart from those animals in Exp. 2 which were naturally mated, donors were surgically inseminated into the tip of the uterine horns with (a) 'fresh semen', (b) 'washed semen' or (c) 'uterine semen'.

'Washed semen' was prepared in Exp. 1 by repeated washing and centrifug-

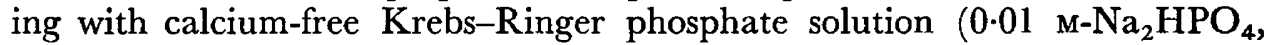
$\left.0.005 \mathrm{~m}-\mathrm{KCl}, 0.001 \mathrm{~m}-\mathrm{KH}_{2} \mathrm{PO}_{4}, 0.001 \mathrm{M}-\mathrm{MgSO}_{4}, 0.132 \mathrm{M}-\mathrm{NaCl}\right)$ or with normal saline in Exp. 2. To $0.5 \mathrm{ml}$ of fresh semen collected by artificial vagina was added $9.5 \mathrm{ml}$ diluent, the sample was centrifuged at $1500 \mathrm{rev} / \mathrm{min}$ for 10 min and $9 \mathrm{ml}$ of the supernatant was then removed and replaced with fresh diluent. The sedimented spermatozoa were resuspended by shaking and again centrifuged. This procedure was repeated a further four times. The sedimented 'semen' obtained after the final centrifugation was used for insemination.

TABLE 1

DESIGN OF THE EXPERIMENTS

\begin{tabular}{|c|c|c|}
\hline \multirow{2}{*}{ Treatment of semen before insemination } & \multicolumn{2}{|c|}{ No. of fertilized eggs } \\
\hline & Stained* & $\begin{array}{l}\text { Transferred to } \\
\text { recipient ewes }\end{array}$ \\
\hline $\begin{array}{l}\text { Experiment 1 } \\
\text { 1. 'Fresh semen'-freshly ejaculated } \\
\text { 2. 'Washed semen'-washed with } \\
\text { calcium-free Krebs-Ringer solution } \\
\text { 3. 'Uterine semen'-recovered from } \\
\text { naturally mated ewes }\end{array}$ & $\begin{array}{l}20 \\
21 \\
18\end{array}$ & $\begin{array}{l}19 \\
20 \\
18\end{array}$ \\
\hline $\begin{array}{l}\text { Experiment } 2 \\
\text { 1. 'Fresh semen'-freshly ejaculated } \\
\text { 2. 'Washed semen'-washed with } \\
\text { normal saline } \\
\text { 3. 'Uterine semen'-recovered from } \\
\text { naturally mated ewes } \\
\text { 4. Nil-donors naturally mated }\end{array}$ & $\begin{array}{l}14 \\
11 \\
19 \\
21\end{array}$ & $\begin{array}{l}29 \\
28 \\
40 \\
35\end{array}$ \\
\hline Total & 124 & 189 \\
\hline
\end{tabular}

* Fate of recipients: Exp. 1-embryos recovered; Exp. 2 lambed.

'Uterine semen' was obtained by flushing the Fallopian tubes and uterine horns of the naturally mated ewes with $10 \mathrm{ml}$ of calcium-free Krebs-Ringer phosphate solution (Exp. 1) or normal saline (Exp. 2). The flushings were centrifuged at $1500 \mathrm{rev} / \mathrm{min}$ for $10 \mathrm{~min}$ and the supernatant was removed to leave 0.2 to $0.4 \mathrm{ml}$ of diluent and sediment. The sediment was resuspended in the remaining diluent and a small sample was taken for examination. A number of samples which contained few, or no, progressively motile spermatozoa were discarded.

Ewes were inseminated under local Xylocaine anaesthesia, 12 to $27 \mathrm{hr}$ after they were first observed in oestrus. No attempt was made to control the number of spermatozoa inseminated. Each ewe received 0.02 to $0.04 \mathrm{ml}$ semen irres- 
pective of its treatment and inseminations were made into both uterine horns with the volume of inseminate approximately equally divided between each horn.

\section{Recovery of eggs}

Eggs were recovered by flushing the Fallopian tubes and portions of the uterine horns of donor ewes with sterile sheep serum $60 \mathrm{hr}$ after they were first detected in oestrus. This interval was adopted to ensure that the majority of fertilized eggs had cleaved at least once by the time they were recovered. Cleavage was taken as the criterion of fertilization and fertilized eggs collected from individual donors were approximately equally divided between those destined for cytological examination and those destined for transfer. An attempt was made to attain uniform numbers of eggs within groups. However, variations in numbers of eggs recovered, or in numbers of eggs fertilized, made impractical the achievement of uniform group size.

\section{Examination of eggs}

Cleaved eggs destined for cytological study were examined as unstained preparations and then were re-examined after staining with $1 \%$ orcein. They were classed as normal or abnormal:

Normal

Abnormal
All cells of approximately equal size, with one nucleus in each cell.

Type 1. Anucleate particles present.

Type 2. Multinucleate cells present.

All one-cell eggs recovered from donor ewes were examined for evidence of fertilization.

\section{Transfer of eggs}

Transfers were made to the Fallopian tubes of recipient ewes which had been first observed in oestrus within $\pm 12 \mathrm{hr}$ of their respective donors, and each recipient received one egg. Recoveries and transfers were carried out under general anaesthesia with Nembutal.

\section{Recovery of embryos}

Embryos were recovered from recipients on the 16th day after the transfer oestrus (i.e. 13 to 14 days after transfer) by flushing the uteri in vivo with $10 \mathrm{ml}$ normal saline. The flushings were collected through a 5-mm bore glass cannula inserted into the tip of one uterine horn. Embryos and their associated membranes were examined under a dissecting microscope ( $\times 20$ magnification).

\section{Lambing}

During lambing, the recipients were inspected at least once daily and newly born lambs were identified. 


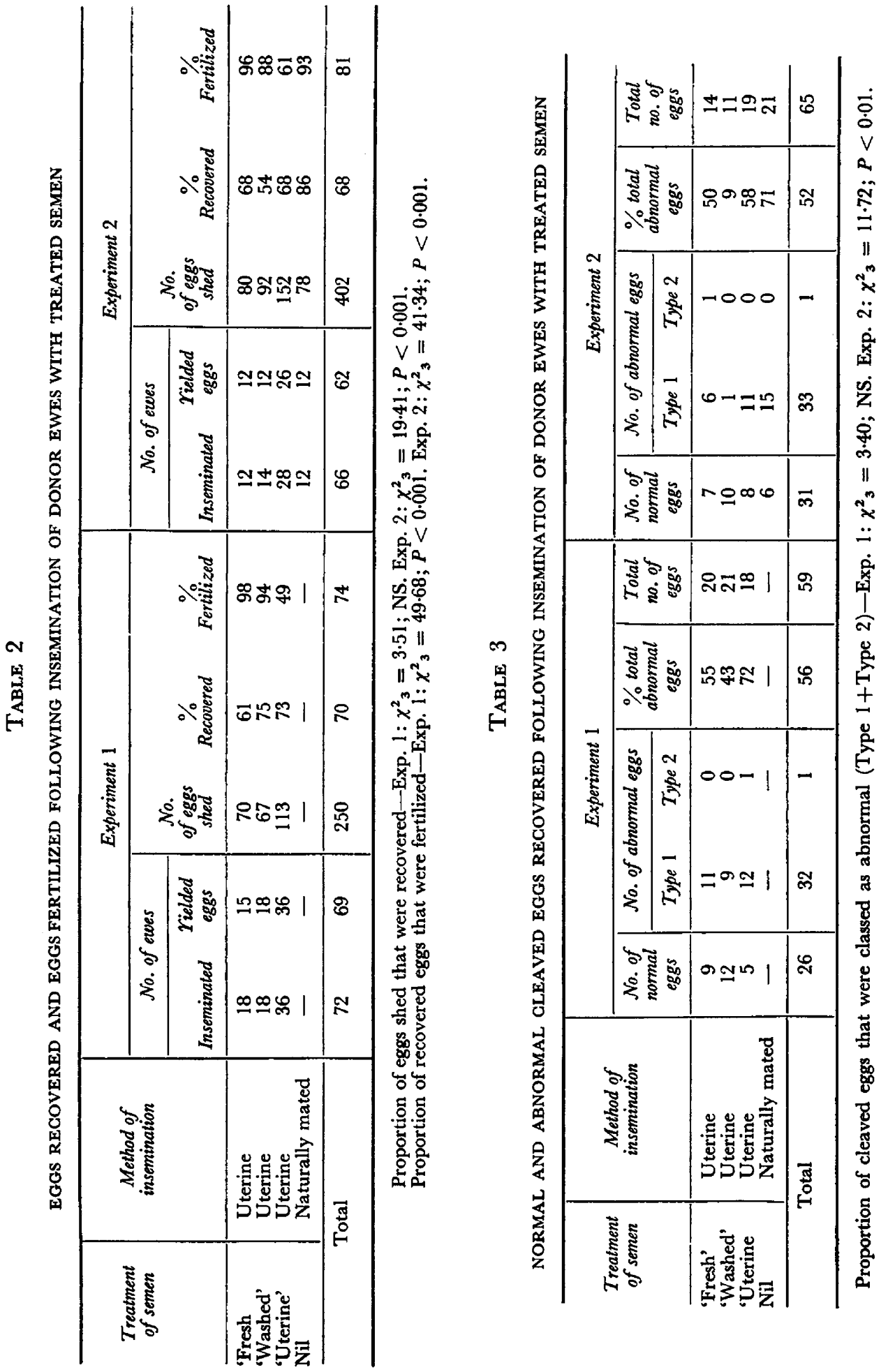




\section{RESULTS}

In the two experiments, 449 eggs were recovered from 131 of 138 donor ewes (Table 2). In Exp. 1, there was no effect of any treatment on the proportion of eggs that were recovered while, in Exp. 2, there was an effect of treatment $(P<$ $0.001)$ due to the high rate of recovery $(86 \%)$ from naturally mated donors. In both experiments, there was a marked reduction in the proportion of eggs that were fertilized following insemination with 'uterine semen'.

Ninety-nine uncleaved eggs were recovered, of which eighty-two were from ewes inseminated with 'uterine semen'. Only eight had spermatozoa attached to their zonae, of which five showed definite evidence of penetration by spermatozoa. None of the remaining eggs showed any evidence of having been fertilized.

The cell stage of the $\mathbf{3 5 0}$ fertilized cleaved eggs ranged from two to eight cells with the majority (301) of four to eight cells. There was no effect of any treatment on the distribution of cell stage.

\section{TABLE 4}

RECIPIENTS WHICH HAD EMBRYOS OR LAMBS FOLLOWING THE TRANSFER OF GLEAVED EGGS GOLLEGTED FROM EWES INSEMINATED WITH TREATED SEMEN

\begin{tabular}{|c|c|c|c|c|c|}
\hline \multirow{3}{*}{$\begin{array}{l}\text { Treatment } \\
\text { of semen }\end{array}$} & \multirow{3}{*}{$\begin{array}{c}\text { Method of } \\
\text { insemination }\end{array}$} & \multicolumn{4}{|c|}{ Recipients } \\
\hline & & \multicolumn{2}{|c|}{ Experiment 1} & \multicolumn{2}{|c|}{ Experiment 2} \\
\hline & & $\begin{array}{c}\text { Total } \\
\text { no. }\end{array}$ & $\begin{array}{l}\% \\
\text { with an } \\
\text { embryo }\end{array}$ & $\begin{array}{c}\text { Total } \\
\text { no. }\end{array}$ & $\begin{array}{l}\% \\
\text { which } \\
\text { lambed }\end{array}$ \\
\hline $\begin{array}{l}\text { 'Fresh' } \\
\text { 'Washed' } \\
\text { 'Uterine' } \\
\text { Nil }\end{array}$ & $\begin{array}{l}\text { Uterine } \\
\text { Uterine } \\
\text { Uterine } \\
\text { Naturally mated }\end{array}$ & $\begin{array}{l}19 \\
20 \\
18 \\
\end{array}$ & $\begin{array}{l}63 \\
45 \\
33 \\
-\end{array}$ & $\begin{array}{l}29 \\
28 \\
40 \\
35\end{array}$ & $\begin{array}{l}59 \\
43 \\
53 \\
51\end{array}$ \\
\hline Total & & 57 & 47 & 132 & 52 \\
\hline
\end{tabular}

Proportion of recipients in which eggs survived-Exp. $1: \chi^{2}{ }_{2}=3 \cdot 27$; NS. Exp. $2: \chi^{2}{ }_{3}=1 \cdot 44 ; \mathrm{NS}$.

\section{Examination of eggs}

Twenty-four cleaved eggs were lost or fractured before examination was completed and have been excluded from the experiment. In all, sixty-seven of the 124 cleaved eggs available for morphological study were classed as 'abnormal' (Table 3). Sixty-five contained one or more anucleate particles (Type 1Pl. 1, Figs. 1 to 3 ) and the remaining two had one multinucleate cell.

Frequently, Type 1 eggs contained more than one anucleate particle, but these were invariably associated with normal nucleated blastomeres. The size of particles varied from that of a polar body to that of a normal blastomere. Type 1 'abnormal' eggs invariably showed nothing more unusual than one or more anucleate particles.

In Exp. 1, 'abnormal' eggs were equally distributed between the various 


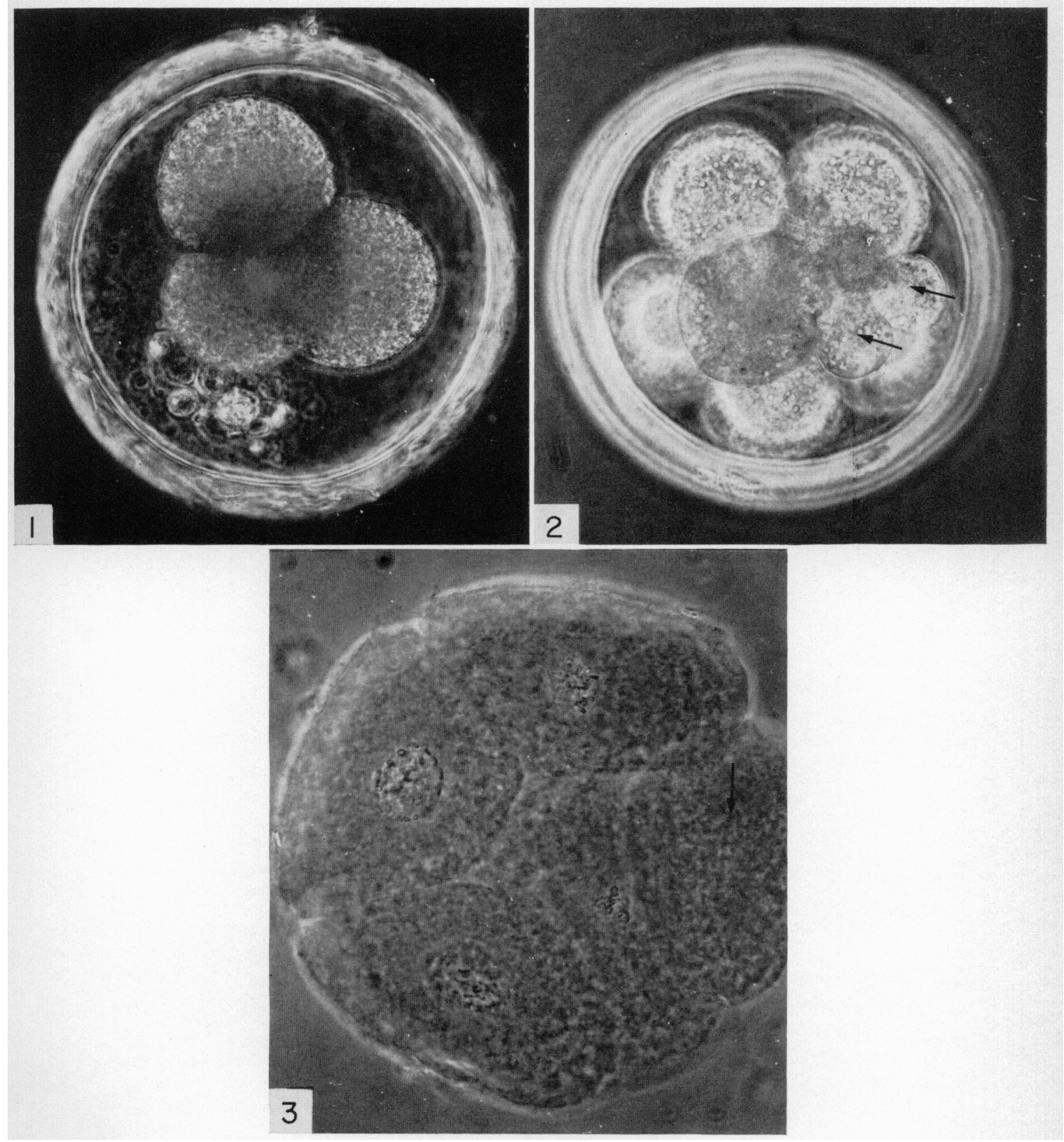

All figures are phase contrast photoniserographs of abonomal Type 1 iggs.

lik. I. A four-cell egg which contained numerous small anucleate partictes. Fresh preparalio1], $\times 280$.

Fu. 2. A serentedl egg which contained tive anucleate particles. Two of the particles arrowed can be distinguished in the photegraph. Fesh preparation. $\times 280$

lis: 3. A four-cell egg which contained an andeleate particle arrowed : Orecin staned jerparation. $\times 140$. 
treatments, whereas, in Exp. 2, there was an effect of treatment due to a low incidence in ewes inseminated with 'washed semen'.

\section{Development following transfer}

In Exp. 1, twenty-seven of fifty-seven ewes had embryos and, in Exp. 2, sixty-eight of 132 recipients lambed (Table 4). None of the embryos or lambs showed any obvious abnormalities and there was no effect of any treatment on the proportion of eggs which survived to become embryos or lambs.

\section{DISCUSSION}

Apart from ewes inseminated with 'uterine semen', very high rates of fertilization were achieved by uterine insemination. It is apparent that low lambing performances reported following uterine insemination (Salamon \& Lightfoot, 1967; Mattner et al., 1969; Killeen, 1969) are not due to failure of fertilization. The low fertilization rates recorded in both experiments following insemination with 'uterine semen' were probably due to the poor quality of the semen. A number of samples used, particularly in Exp. 1, contained few progressively motile spermatozoa.

Eggs fertilized by uterine insemination were viable and capable of normal development when transferred to recipients. Although the survival of transferred eggs was somewhat lower than could be expected (Moore \& Rowson, 1960; Moore \& Shelton, 1964), the proportion that did develop to become normal embryos or lambs was not affected by the method of insemination, or by treatment of semen before surgical insemination.

More than half of the eggs examined were classed as 'abnormal' and the greatest incidence $(71 \%$ ) was recorded in ewes which had been naturally mated. Clearly, uterine insemination was not responsible for such abnormalities, nor did the presence of seminal plasma at or near the site of fertilization affect fertilization or the subsequent development of fertilized eggs.

Multinucleate cells, as observed in Type 2 'abnormal' eggs, represent gross aberrations and such eggs may very well be incapable of full development. However, the low incidence of these eggs-two of 124 examined-suggests that they are of little consequence. Anucleate particles, as observed in Type 1 'abnormal' eggs, may be of little or no importance. The high incidence of this type of egg, particularly in naturally mated ewes, strongly suggests that they are in fact normal in so far as further development is concerned and should be classed as 'atypical' rather than 'abnormal'. Hancock \& Hovell (1961) recorded that fertilized sheep eggs with irregular sized blastomeres were capable of full development and Killeen (1969) suggested that eggs similar to those of Type 1 observed in the present study were viable. The low incidence of Type 1 eggs in ewes inseminated with washed semen in Exp. 2 is difficult to explain, particularly as, in Exp. 1, similar treatment resulted in a high incidence of eggs with anucleate particles.

The low proportion of eggs recovered following uterine insemination may indicate the reason for the poor lambing performances recorded following uterine insemination. Overall, uterine insemination gave high fertilization rates 
in eggs recovered, but the proportion recovered was relatively low. Thus, 20 to $30 \%$ less eggs were recovered following uterine insemination than after natural mating in Exp. 2. Surgical interference with the tract seems to result either in expulsion or rapid transport of eggs. Rapid transport would seem to be implicated as the authors (unpublished data) have obtained high recovery rates, as well as high fertilization rates, following uterine insemination when $\mathbf{4 8}$ $\mathrm{hr}$, or less, elapsed between insemination and recovery of eggs. In the present study, $60 \mathrm{hr}$ elapsed between insemination and recovery. Thus, it seems that the low lambing performances observed following surgical insemination are due to abnormal transport of eggs resulting from surgical interference.

\section{ACKNOWLEDGMENTS}

Grateful acknowledgment for technical assistance is made to $\mathrm{Mr} \mathrm{A}$. D. Barnes, Mr R. W. Connors, Mr C. J. Hodges, Mr J. E. McRae, Miss Narelle Flett and Mrs Margaret Jeffery.

Financial support was provided by the Australian Research Grants Committee and the Australian Wool Board. One of us (I.D.K.) was the recipient of a Wool Board Postgraduate Fellowship. PMSG was generously donated by G. D. Searle \& Co., Chicago.

\section{REFERENCES}

Averill, R. L. W. \& Rowson, L. E. A. (1958) Ovum transfer in the sheep. F. Endocr. 16, 326.

Grang, M. C. (1950) The effect of seminal plasma on fertilized rabbit ova. Proc. natn. Acad. Sci. U.S.A. $36,188$.

HADEK, R. (1959) Study of the sperm capacitation factor in the genital tract of the female rabbit. Am. F. vet. Res. 20, 753.

Hancock, J. L. \& Hovell, G. J. R. (1961) Transfer of sheep ova. F. Reprod. Fert. 2, 520.

KILLEEN, I. D. (1969) Studies on fertilization and early development of the ovine ovum. Ph.D. thesis, University of Sydney.

Mattner, P. E., Entwistle, K. W. \& Martin, I. C. A. (1969) Passage, survival and fertility of deepfrozen ram semen in the genital tract of the ewe. Aust. F. biol. Sci. 22, 181.

Moore, N. W. \& Rowson, L. E. A. (1960) Egg transfer in sheep. Factors affecting the survival and development of transferred eggs. F. Reprod. Fert. $1,332$.

Moore, N. W. \& Shelron, J. N. (1964) Egg transfer in sheep. Effect of degree of synchronization between donor and recipient, age of egg, and site of transfer on the survival of transferred eggs. 7. Reprod. Fert. 7, 145.

Salamon, S. \& Lightfoot, R. J. (1967) Fertilization and embryonic loss in sheep after insemination with deep frozen semen. Nature, Lond. 216, 194. 